\section{Fatal and non-fatal repetition of self-harm}

\author{
Systematic review
}

DAVID OWENS, JUDITH HORROCKS and ALLAN HOUSE
We estimate that around a quarter of suicides are preceded by non-fatal self-harm in the previous year (Owens \& House, 1994). If so, an episode of self-harm ranks with recent discharge from in-patient psychiatric care as the major risk factor for suicide (Gunnell \& Frankel, 1994). This estimate of the link between self-harm and suicide needs to be accurate if we are to plan services aimed at reduction in suicide rate - a governmental priority for health improvement in the UK over recent years (Department of Health, 1999; Secretary of State for Health, 1999) and the target of a recent initiative by the USA Surgeon General (Vastag, 2001). Suicide is, nevertheless, too infrequent to be the main outcome event for a clinical trial of intervention after non-fatal self-harm. Instead, trials will continue to be designed to determine whether an intervention reduces the non-fatal repetition rate. Consequently, reliable estimates of repetition rate are needed for power calculation. We have undertaken a systematic review of the published literature in order to produce the best available estimates of rates of subsequent suicide and of non-fatal repetition following self-harm.

\section{METHOD}

Search strategies for the four databases Cinahl, Embase, Medline and PsycLit (each searched from their earliest entries) were constructed in 1998 for a non-systematic review (NHS Centre for Reviews and Dissemination, 1998) by an expert database searcher at the UK National Health Service Centre for Reviews and Dissemination, in conjunction with our clinical research team. We updated the strategies and ran them again in April 2001 for the present review. Ten journals were hand-searched for the Cochrane review of self-harm treatment trials (Hawton et al, 2001) but no extra hand-searching was carried out for the present review.
From the primary studies and all their secondary references, we included in our review every research report that fulfilled four criteria. The studies we selected were written in English, were published after 1970, described patients recruited to a study after attending a general hospital as a result of an episode of non-fatal self-harm and reported the proportion that repeated self-harm - fatally or not - for any followup period of at least a year. Suicides in most primary studies included those that were definite (by verdict of a coroner or equivalent authority) or probable (open verdicts or equivalent judgement); definitions were too variable for us to discriminate further and we have included them all and used the above broad definition of suicide. Because our search strategy found only one small study from the Far East that met the above criteria, we excluded it; the final list consequently represents research from Europe, North America and Australasia.

We excluded studies where the sample was restricted to participants who were young or elderly or had a learning disability. We did not exclude primary studies whose subjects were selected according to some measure of severity, such as established multiple repetition of self-harm or attending for the first time. Instead, we combined all the data and then applied a quality scale (described below). The majority of the studies were observational in design. Where we used data from clinical trials we combined data from both treatment groups, because the Cochrane review of trials of self-harm management (Hawton et al, 2001) found no clear difference between outcomes for experimental interventions compared with treatment as usual. Where more than one published paper set out findings for the same sample, we extracted results from the most complete version.

\section{Measuring the quality of the primary study findings}

For each study reporting a 1 -year rate of non-fatal repetition or suicide we applied a ten-point quality scale based on features of the method and analysis (Table 1).

\section{Study size}

We weighted the quality score in favour of larger studies because they estimate outcome with the greatest precision. Clinical trials tend to score low in these ratings because of small sample size. We previously 
Table I Non-fatal repetition and suicide: quality scores for study estimates

\begin{tabular}{|c|c|c|}
\hline & Repetition scale & Suicide scale \\
\hline \multicolumn{3}{|l|}{ Size } \\
\hline$n=\mathbf{2 0 0}$ or more & 1 & \\
\hline$n=600$ or more & $\mathbf{I}$ & \\
\hline$n=500$ or more & & I \\
\hline$n=950$ or more & & I \\
\hline \multicolumn{3}{|l|}{ Sample } \\
\hline No obvious bias to mild or severe cases & I & I \\
\hline No deliberate exclusions & $\mathbf{I}$ & I \\
\hline All admitted cases included & I & 1 \\
\hline Accident and emergency sample & 1 & 1 \\
\hline \multicolumn{3}{|l|}{ Ascertainment of outcome } \\
\hline Individual subjects followed up ( $90 \%$ or more) & & I \\
\hline National death records consulted & & 1 \\
\hline Catchment area targeted & $1 / 2$ & \\
\hline Subjects interviewed ( $80 \%$ or more) & $1 / 2$ & \\
\hline General practitioner records consulted ( $80 \%$ or more) & $1 / 2$ & \\
\hline Accident and emergency records checked & $1 / 2$ & \\
\hline \multicolumn{3}{|l|}{ Analysis of data } \\
\hline Proper denominator (uniform time or at-risk period) & 1 & $\mathrm{I}$ \\
\hline Survival methods with censorship & I & 1 \\
\hline Total & 10 & 10 \\
\hline
\end{tabular}

found (NHS Centre for Reviews and Dissemination, 1998) that, for the studies reporting repetition of non-fatal self-harm within 1 year, the median proportion repeating was $16 \%$. A follow-up study of 200 subjects $(n=200)$ would generate a $95 \%$ confidence interval of $11-21 \%$ (or $16 \pm 5 \%$ ) around a sample estimate of $16 \%$ (Gardner et al, 1989). A more precise estimate can be derived from $n=600$ : $13-19 \%$ (or $16 \pm 3 \%$ ).

Because suicide is a rare outcome event, large sample sizes are needed for precise estimates. In the same way, we used the median from our previous review (3\% suicide at 1-4 years of follow-up) to determine reasonably precise and achievable estimates: $n=500$ would generate a $95 \%$ confidence interval of $1.5-4.5 \%$ (or $3 \pm 1.5 \%$ ); $n=950$ provides a more precise estimate of approximately $2-4 \%$ (or $3 \pm 1 \%$ ).

\section{Study sample}

All hospitals discharge home a substantial proportion of patients attending as a consequence of self-harm (Owens, 1990), which is as many as two-thirds from some accident and emergency departments (Kapur et al, 1998). Comprehensive studies of hospital contact therefore identify subjects at accident and emergency or equivalent walk-in or emergency departments at general or psychiatric hospitals. The next best procedure is to ensure that all cases admitted as in-patients are included. Weaker designs use convenience samples such as lists of weekday routine referrals to the selfharm assessment service; there will be exclusion biases but it is not clear what they might be. The most obvious biases of all occur when studies confine their sample to mild or to severe cases, perhaps to first-time or to multiple-repeat patients. We awarded up to four points for sampling (see Table 1); the final score is a cumulative one according to the absence of noticeable bias. Clinical trials usually had numerous exclusions and tended to score low.

\section{Ascertainment of outcome}

We found that the studies determined subsequent suicides by one or more of three methods: by inspection of local coroners' (or equivalent) records, looking for the names of the study subjects; by efforts to determine the whereabouts of each patient, for example using hospitals, general practitioners and their records; and by checking names and other personal details against national registration of deaths. The first of these methods is weak - missing those who move home, even by only a short distance, and those who change their names. We awarded a point each for use of the two better methods.

Non-fatal repetition is more difficult to determine because of inadequate collection of data in most hospitals. We awarded half a point each for four steps taken to maximise identification of all the repeat episodes: use of a catchment area for the inclusion of subjects; interview follow-up of subjects; checks in general practice records; and checking of accident and emergency records.

\section{Analysis of data}

Many studies wrongly estimated the proportion repeating by recruiting subjects over a long period and following them up to a single end-point, failing to correct for the difference between subjects in the time-period denominator. Where a study used a uniform follow-up period-for example, everyone followed up for exactly 1 year from the date of inclusion - we awarded a point. Studies that used survival analysis scored a further point.

\section{Combining the studies into a summary}

The studies emerging from the literature search included single group cohorts, cohort analytical studies and clinical trials. This body of research is too heterogeneous for meta-analysis (Egger et al, 1998). Instead, we have placed the findings in rank order and we report their medians together with their interquartile range (25th-75th centiles).

\section{RESULTS}

The search strategy identified 90 studies meeting our inclusion criteria. Studies from the UK and Ireland accounted for over one-third $(36 \%)$ of all the investigations. The others were undertaken in Scandinavia and Finland (26\%), the rest of Europe (19\%), North America (11\%) and Australia and New Zealand (8\%).

The main results of our analysis, grouped by duration of follow-up, are shown in Fig. 1. The median proportion repeating non-fatal self-harm is $16 \%$ at 1 year and $23 \%$ in studies lasting longer than 4 years. For subsequent suicide, the increment in the median after a longer 


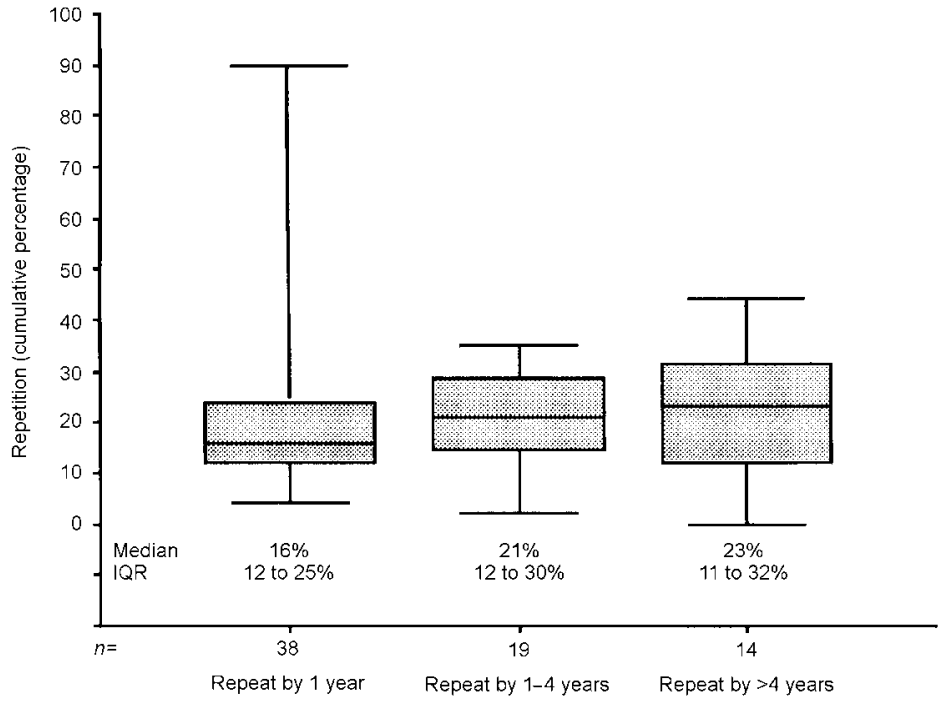

(a) Repetition according to duration of follow-up

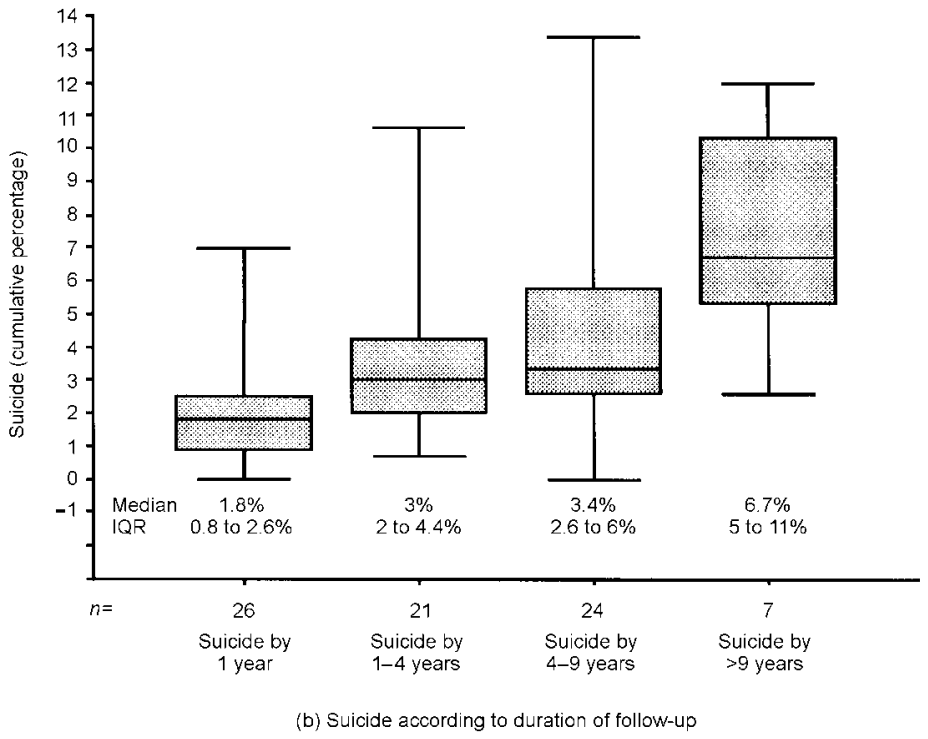

Fig. I Repetition and suicide studies grouped according to duration of study. Medians are indicated by horizontal bars. Vertical bars indicate the range and the horizontal boundaries of the boxes represent the first and third quartiles. IQR, interquartile range.

follow-up is relatively much more - from less than $2 \%$ at 1 year up to nearly four times greater in the studies lasting over 9 years.

\section{Subgroup analyses}

For repetition at 1 year and suicide at 1 year we rank-ordered the studies according to date of publication and compared the findings of the more recent and older halves (Figs 2a and 3a). Medians were largely unaffected by the split but there was a wider dispersion of values among the studies in the past 10 years. studies are shown in Figs $2 c$ and 3c. For repetition and then for suicide we placed the studies in rank order according to quality score and then compared the better findings (those above the whole-group median score) with those below the median. For repetition, the values for the better-quality findings bunch tightly around $15 \%$ (a similar median to the one we found for all 37 studies); for the poorer-quality findings, the values are more dispersed around a higher median $(21 \%)$. Examining suicide, we find a similar pattern: the higher-quality findings are tightly grouped around a median $(1.8 \%)$ identical to that of the whole group of 26 studies, and the poorer-quality findings are far more widely dispersed around a slightly higher median.

Figure 4 shows a larger proportion of high-quality findings among the reports of non-fatal repetition than among the reports of subsequent suicide. We might have predicted this disparity because we were aware of few large studies that could estimate suicide with precision.

\section{DISCUSSION}

\section{Systematic reviewing} of observational research

Search strategies and safeguards against publication bias are less well developed for reviews of observational studies than they are for clinical trials. Although we are likely to have missed studies from our review, the tight clustering around the medians in higher-quality studies indicates that we would have to unearth many good studies with findings in one direction before medians for repetition or suicide would shift very far.

We were struck by the relative absence of studies from the USA, in line with the few American studies about intervention following self-harm (Hawton et al, 2001). Publication bias seems an unlikely explanation; our search terms used standard procedures, and three of the four bibliographical databases that we used are American and thereby likely to bias in favour of American studies. Clinical epidemiological study of self-harm is uncommon in the USA, despite the huge scale of self-harm there (Vastag, 2001).

\section{Summary of quantitative findings}

Summing up our findings, it seems that a reasonable estimate of non-fatal repetition is $15-16 \%$ at 1 year with a slow rise to 


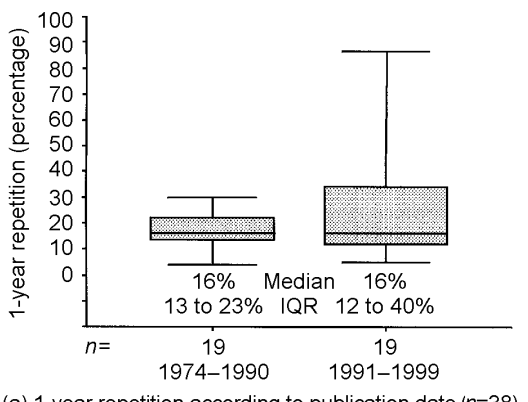

(a) 1-year repetition according to publication date $(n=38)$

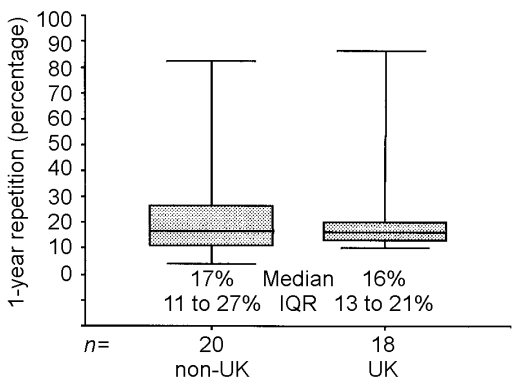

(b) 1-year repetition according to study location ( $n=38$ )

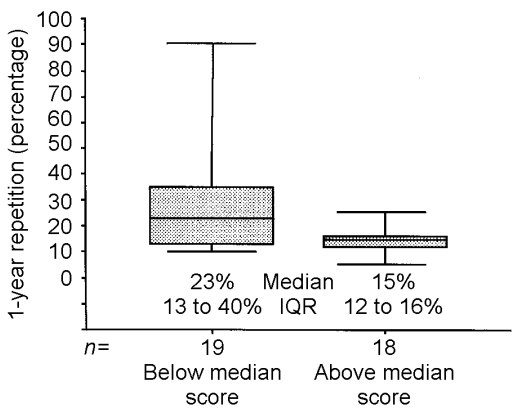

(c) 1-year repetition according to quality rating ( $n=37)$ and divided according to date of publication, location and quality score. IQR, interquartile range.
Fig. 2 Repetition within I year: studies grouped

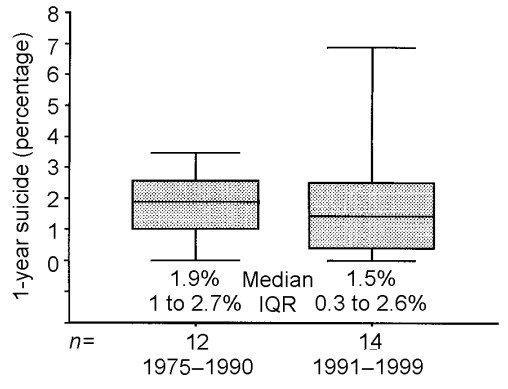

(a) 1 -year suicide according to publication date $(n=26)$

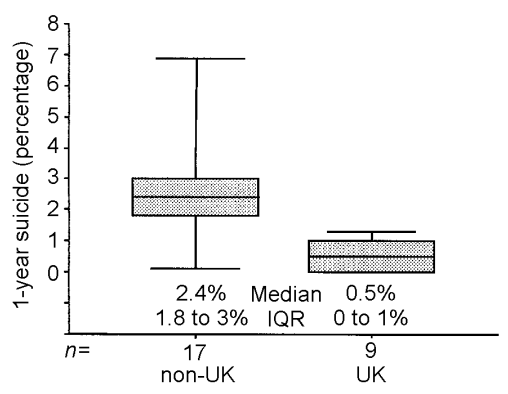

(b) 1-year suicide according to study location $(n=26)$

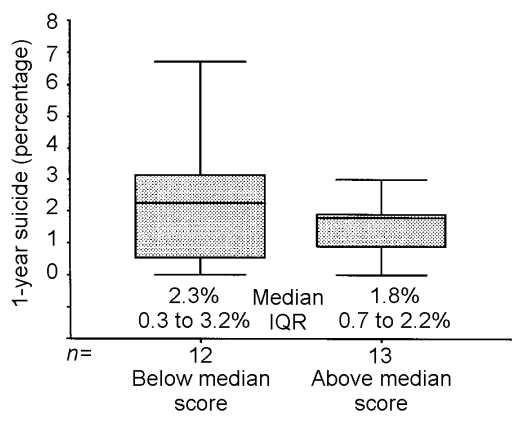

(c) 1-year suicide according to quality rating $(n=25)$

Fig. 3 Suicide within I year: studies grouped and divided according to date of publication, location and quality score. IQR, interquartile range.

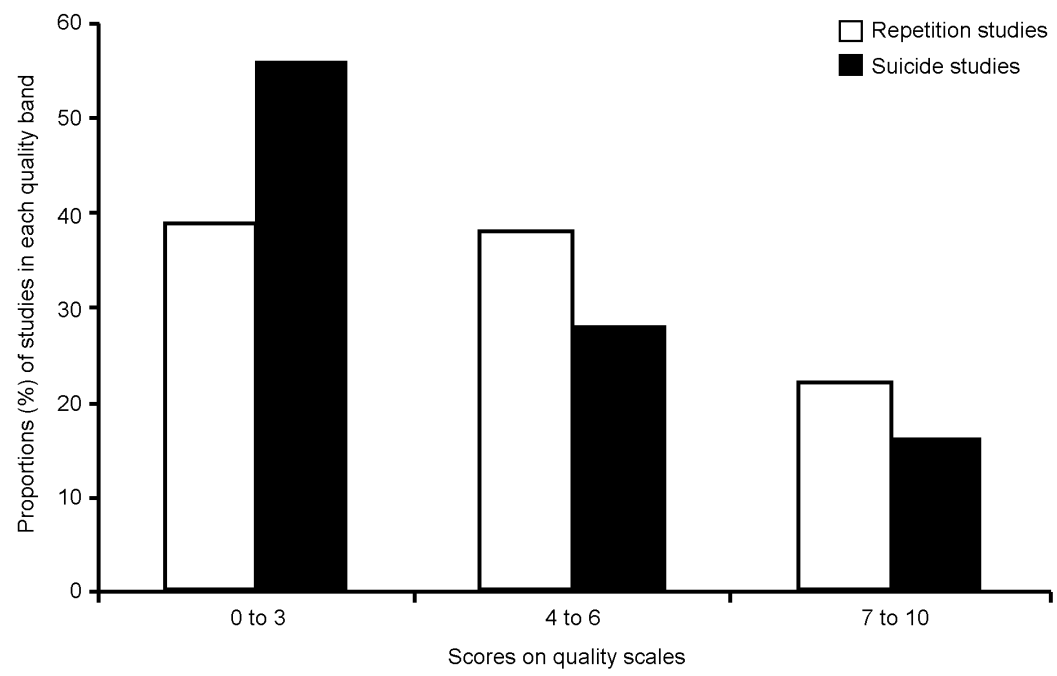

Fig. 4 Frequency distributions of the I-year quality scores for repetition and suicide.
$20-25 \%$ over the following few years. In this review we have not been able to determine the 1-year repetition rate of an inception cohort (first-time self-harm cases). For suicide following self-harm we cannot settle on a simple finding. The median 1-year suicide rate for the better half of all the studies reviewed was four times higher than the median rate for all UK studies (Fig. 3), which might point to real differences in outcome according to location or to deficits in either the UK or non-UK literature.

\section{Why were suicide findings inconsistent?}

Quality scores in the suicide studies were generally low, with a median quality score for all 26 studies of only 2.5 out of 10 (interquartile range 2-5). Scores for the 9 UK studies were not noticeably different from those of the 17 non-UK studies: UK study median quality score $=2(2-5.5)$ and nonUK median $=3(1-5)$, a difference without statistical significance (Mann-Whitney $W=$ 212, $P=0.6$ ).

We checked whether health service differences between the UK and elsewhere might have led the UK studies to concentrate on accident and emergency departments, thereby biasing their samples towards those less severe episodes that result in discharge from accident and emergency. In 2 out of 9 UK studies and 4 out of 17 studies from other countries, the researchers followed up all the patients who attended, not just the admitted patients. Similarly, we found the same median scores for sampling (out of a maximum of four) in UK and non-UK studies: zero for each group, with the same upper quartiles of 3.5. We therefore found no evidence of a group difference based on differential attention to patients attending hospital and leaving without in-patient admission.

\section{Consequences of the inconsistent findings about suicide}

Although our review might suggest that suicide following self-harm has a substantially lower incidence in the UK than elsewhere, the cumulative findings about suicide after self-harm are too flimsy to rely on. We need to understand the links between non-fatal self-harm and suicide if we are to plan clinical services and intervention research properly. The best current UK estimate of hospital attendance due to self-harm is around 400 per 100000 (Hawton et al, 1997); $0.5 \%$ incidence of suicide in the 
next year after self-harm (our median estimate for UK studies) accounts for 2 per 100000 population, which is one-fifth of the England and Wales suicide rate of 10 per 100000 . If the same calculation is applied to our $1.8 \%$ median estimate from the better-quality studies, then around two-thirds of suicides ( 7 per 100000 ) might be preceded by non-fatal self-harm in the preceding year.

Whichever estimate is the closer to the truth, it is plain that national suicide prevention strategies ought to be based on up-to-date research into non-fatal selfharm. High-quality follow-up studies of self-harm will help to keep those strategies relevant to clinical needs. The studies that ought to be undertaken will be large, following up well over 1000 self-harm patients, and they will be based on all patients attending hospital, regardless of whether or not they were admitted from accident and emergency. Determining the outcome of those who are treated only in primary care will be feasible only when there is an increase in data-sharing in primary care. Repetition will be ascertained from accident and emergency or other hospital contact records, rather than from ward, special unit or discharge data. Suicides will be determined by the use of national records of the registration of deaths. The study data will be analysed using the statistical techniques of survival analysis.

Suicide is a rare event occurring in 1 in 10000 people a year, and bringing about a reduction in the population's suicide rates is a difficult challenge. Recent non-fatal self-harm indicates a large increase in individual risk - it is probably the major risk factor-but the incidence among these people rises to around $1 \%$. Unfortunately, all our clinical methods for predicting suicide among our patients have a very poor positive predictive value at this low level of incidence (Geddes, 1999). Only a population strategy (Rose, 1992) is likely to achieve a reduction in the suicidal potential after self-harm - through application of an intervention aimed at all self-harm patients. But current evidence tells us that the few clinical trials of intervention after self-harm are characterised by inadequate power, unrepresentative samples and unsuitable data analysis (Hawton et al, 1998). The second research need is therefore for the first-ever large, well-designed clinical trial of brief intervention after non-fatal self-harm.

\section{ACKNOWLEDGEMENTS}

We thank Julie Glanville of the NHS Centre for Reviews and Dissemination at the University of York for the first systematic search and Lesley Patchett of the School of Medicine at the University of Leeds for locating and organising the studies.

\section{APPENDIX - STUDIES REVIEWED}

Adam, K. S., Isherwood, J., Taylor, G., et al (198I) Attempted suicide in Christchurch: three-year followup of 195 patients. New Zealand Medical Journal, 93, 376-38I.

_ , Valentine, J., Scarr, G., et al (1983) Follow-up of attempted suicide in Christchurch. Australian and New Zealand journal of Psychiatry, 17, 18-25.

Allard, R., Marshall, M. \& Plante, M. C. (1992) Intensive follow-up does not decrease the risk of repeat suicide attempts. Suicide and Life-Threatening Behavior, 22, 303-314.

Allgulander, C. \& Fisher, L. D. (1990) Clinica predictors of completed suicide and repeated selfpoisoning in 8895 self-poisoning patients. European Archives of Psychiatry and Neurological Sciences, 239 270-276

Aoun, S. (1999) Deliberate self-harm in rural Western Australia: results of an intervention study. Australian and New Zealand Journal of Mental Health Nursing, 8, 65-73.

Arensman, E., Kerkhof, A. J., Hengeveld, M.W., et a (1995) Medically treated suicide attempts: a four year monitoring study of the epidemiology in The Netherlands. Journal of Epidemiology and Community Health, 49, 285-289.

Bancroft, J. \& Marsack, P. (1977) The repetitiveness of self-poisoning and self-injury. British Journal of Psychiatry, I3I, 394-399.

Batt, A., Eudier, F., Le Vaou, P., et al (1998) Repetition of parasuicide: risk factors in general hospital referred patients. Journal of Mental Health, 7, 285-297.

Bille-Brahe, U. \& Jessen, G. (1994) Repeated suicidal behavior: a two-year follow-up. Crisis, 15, 77-82.

Bocchetta, A., Ardau, R., Burrai, C., et al (1998) Suicidal behaviour on and off lithium prophylaxis in a group of patients with prior suicide attempts. Journal of Clinical Psychopharmacology, 18, 384-389.

Boyes, A. P. (1994) Repetition of overdose: a retrospective 5-year study. Journal of Advanced Nursing, 20, $462-468$.

Braftos, O. (197I) Attempted suicide. A comparative study of patients who have attempted suicide and psychiatric patients in general. Acta Psychiatrica Scandinavica, 47, 38-56.

Buglass, D. \& McCulloch, J. W. (1970) Further suicida behaviour: the development and validation of predictive scales. British Journal of Psychiatry, II6, 483-49I.

_ \& Horton, J. (1974) The repetition of parasuicide: a comparison of three cohorts. British Journal of Psychiatry, 125, 168-174.

\section{Carter, G. L., Whyte, I. M., Ball, K., et al (1999)}

Repetition of deliberate self-poisoning in an Australian hospital-treated population. Medical Journal of Australia, 170, 307-311.

Crawford, M. J. \& Wessely, S. (1998) Does initia management affect the rate of repetition of deliberate self-harm? Cohort study. BMJ, 317, 985-990.
Cullberg, J., Wasserman, D. \& Stefansson, C. G. (1988) Who commits suicide after a suicide attempt? An 8 to 10 year follow up in a suburban catchment area. Acta Psychiatrica Scandinavica, 77, 598-603.

Curran, S., Fitzgerald, M. \& Greene, V. (1999)

Psychopathology $81 \frac{1}{2}$ years post parasuicide. Crisis, 20 |15-12|.

Cusick, T. E., Chang, F. C., Woodson, T. L., et al (1999) Is resuscitation after traumatic suicide attempt a futile effort? A five-year review at a Level I trauma centre. American Surgeon, 65, 643-647.

De Moore, G. M. \& Robertson, A. R. (1996) Suicide in the 18 years after deliberate self-harm. A prospective study. British Journal of Psychiatry, 169, 489-494.

Ekeberg, O., Ellingsen, O. \& Jacobsen, D. (1991) Suicide and other causes of death in a five-year followup of patients treated for self-poisoning in Oslo. Acto Psychiatrica Scandinavica, 83, 432-437.

_ , _ \& _ (1994) Mortality and causes of death in a 10 -year follow-up of patients treated for self-poisonings in Oslo. Suicide and Life-Threatening Behavior, 24, 398-405.

Gardner, R., Hanka, R., O'Brien, V. C., et al (1977) Psychological and social evaluation in cases of deliberate self-poisoning admitted to a general hospital. BMJ, ii, I567-1570.

_, _ , Roberts, S. J., et al (1982) Psychological and social evaluation in cases of deliberate self-poisoning seen in an accident department. BMJ, 284, 49I-493.

Garzotto, N., Siani, R., Tansella, C. Z., et al (1976) Cross-validation of a predictive scale for subsequent suicidal behaviour in an Italian sample. British Journal of Psychiatry, 128, 137-140.

Gharagozlou, H. \& Hadjmohammadi, M. (1977) Report on a three-year follow-up of 100 cases of suicidal attempts in Shiraz, Iran. International Journal of Social Psychiatry, 23, 209-210.

Gibbons, J. S., Butler, J., Urwin, P., et al (1978) Evaluation of a social work service for self-poisoning patients. British Journal of Psychiatry, 133, III-118.

Gilbody, S., House, A. \& Owens, D. (1997) The early repetition of deliberate self harm. Journal of the Royal College of Physicians of London, 31, 17I-172.

Greer, S. \& Bagley, C. (197I) Effect of psychiatric intervention in attempted suicide: a controlled study. $B M \mid, i, 310-312$.

Hall, D. J., O'Brien, F., Stark, C., et al (1998) Thirteen-year follow-up of deliberate self-harm, using linked data. British Journal of Psychiatry, 172, 239-242.

Hansen, W. \& Wang, A. G. (1984) Suicide attempts in a Danish region. Social Psychiatry, 19, 197-201.

Hassanyeh, F., O'Brien, G., Holton, A. R., et al (1989) Repeat self-harm: an 18-month follow-up. Acta Psychiatrica Scandinavica, 79, 265-267.

Hawton, K., Bancroft, J., Catalan, J., et al (198I) Domiciliary and outpatient treatment of self-poisoning patients by medical and non-medical staff. Psychological Medicine, II, 169-177.

_ , McKeown, S., Day, A., et al (1987) Evaluation of out-patient counselling compared with general practitioner care following overdoses. Psychological Medicine, 17, 75I-761.

_ \& Fagg, J. (1988) Suicide, and other causes of death, following attempted suicide. British Journal of Psychiatry, 152, 359-366.

_, _ \& McKeown, S. P. (1989) Alcoholism, alcohol and attempted suicide. Alcohol and Alcoholism, 24, 3-9. 
_ , Fagg, J., Simkin, S., et al (1997) Trends in deliberate self-harm in Oxford, 1985-1995. Implications for clinical services and the prevention of suicide. British Journal of Psychiatry, I7I, 556-560.

Hjelmeland, H. (1996) Repetition of parasuicide: a predictive study. Suicide and Life-Threatening Behavior, 26, 395-404.

\section{_ , Stiles, T. C., Bille-Brahe, U., et al (1998)}

Parasuicide: the value of suicidal intent and various motives as predictors of future suicidal behaviour. Archives of Suicide Research, 4, 209-225.

Johnsson, F. E., Ojehagen, A. \& Traskman-Bendz, L. (1996) A 5-year follow-up study of suicide attempts. Acta Psychiatrica Scandinavica, 93, 151-157.

Kaplan, K. J. \& Harrow, M. (1999) Psychosis and functioning as risk factors for later suicidal activity among schizophrenia and schizoaffective patients: disease-based interactive model. Suicide and LifeThreatening Behavior, 29, 10-24.

Kennedy, P., Rogers, B., Speer, S., et al (1999) Spina cord injuries and attempted suicide: a retrospective review. Spinal Cord, 37, 847-852.

Leon, A. C., Keller, M. B., Warshaw, M. G., et al (1999) Prospective study of fluoxetine treatment and suicidal behaviour in affectively ill subjects. American Journal of Psychiatry, 156, 195-201.

Liberman, R. P. \& Eckman, T. (198I) Behaviour therapy vs insight-oriented therapy for repeated suicide attempters. Archives of General Psychiatry, 38, II26-1130.

Linehan, M. M., Armstrong, H. E., Suarez, A., et a (1991) Cognitive-behavioral treatment of chronically parasuicidal borderline patients. Archives of General Psychiatry, 48, 1060-1064.

Lonnqvist, J. \& Karha, E. (1984) Suicide attempts in Helsinki. Psychiatria Fennica, I5, 135-145.

__, Niskanen, P., Achte, K. A., et al (1975) Selfpoisoning with follow-up considerations. Suicide, $\mathbf{5}$ 39-46.

— \& Ostamo, A. (1991) Suicide following the first suicide attempt: a five year follow-up using a survival analysis. Psychiatria Fennica, 22, 17I-179.

McEvedy, C. J. (1997) Trends in self-poisoning admissions to a central London hospital, 1991-1994. Journal of the Royal Society of Medicine, 90, 496-498.

McFarland, B. H. \& Beavers, D. J. (1986) Psychiatric consultation following attempted suicide. Journal of the American Osteopathic Association, 86, 743-750.

McLeavey, B. C., Daly, R. J., Ludgate, J. W., et al (1994) Interpersonal problem-solving skills training in the treatment of self-poisoning patients. Suicide and LifeThreatening Behavior, 24, 382-394.

Moller, H. (1989) Efficacy of different strategies of aftercare for patients who have attempted suicide. Journal of the Royal Society of Medicine, 82, 643-647.

Morgan, H. G., Barton, J., Pottle, S., et al (1976) Deliberate self-harm: a follow-up study of 279 patients British Journal of Psychiatry, 128, 361-368.

_ , Jones, E. M. \& Owen, J. H. (1993) Secondary prevention of non-fatal deliberate self-harm: the Green Card Study. British Journal of Psychiatry, 163, III-|I2.

Muller-Oerlinghausen, B., Muser-Causemann, B. \& Volk, J. (1992) Suicides and parasuicides in a high-risk patient group on and off lithium long-term medication. Journal of Affective Disorders, 25, 261-270.

Nielsen, B., Wang, A. G. \& Bille-Brahe, U. (1990) Attempted suicide in Denmark (IV). A five-year followup. Acta Psychiatrica Scandinavica, 8I, 250-254.

\section{CLINICAL IMPLICATIONS}

- The link between self-harm and suicide is a strong one; subsequent suicide occurs in somewhere between I in $\mathbf{2 0 0}$ and I in $\mathbf{4 0}$ self-harm patients in the first year of follow-up and in around $I$ in 15 people after 9 or more years.

- Non-fatal repetition is common after self-harm; about one in six patients repeats over the next year and one in four after 4 years.

- The UK estimates of rates of suicide after self-harm are low when they are compared with the rest of the research literature.

\section{LIMITATIONS}

- Estimates of fatal and non-fatal repetition after self-harm are derived from an accumulation of small studies rather than from large-scale monitoring.

- Estimates of rates of subsequent suicide are largely derived from poor follow-up data.

- Pooled estimates of subsequent suicide are therefore imprecise.

DAVID OWENS, MD, MRCPsych, JUDITH HORROCKS, MPhil, ALLAN HOUSE, DM, MRCPsych, Academic Unit of Psychiatry and Behavioural Sciences, University of Leeds

Correspondence: David Owens, Academic Unit of Psychiatry and Behavioural Sciences, University of Leeds, I5 HydeTerrace, Leeds LS2 9LT, UK

(First received I3 November 200I, final revision 12 March 2002, accepted 19 March 2002)

Nordentoft, M., Breum, L., Munck, L. K., et al (1993) High mortality by natural and unnatural causes: a 10 year follow up study of patients admitted to a poisoning treatment centre after suicide attempts. BMJ, 306, $|637-| 64 \mid$

Nordstrom, P., Samuelsson, M. \& Asberg, M. (1995) Survival analysis of suicide risk after attempted suicide. Acta Psychiatrica Scandinavica, 91, 336-340.

Ojehagen, A., Regnell, G. \& Traskman-Bendz, L. (1991) Deliberate self-poisoning: repeaters and nonrepeaters admitted to an intensive care unit. Acto Psychiatrica Scandinavica, 84, 266-27I.

_ , Danielsson, M. \& Traskman-Bendz, L. (1992) Deliberate self-poisoning: treatment follow-up of repeaters and nonrepeaters. Acta Psychiatrica Scandinavica, 85, 370-375.

Owens, D., Dennis, M., Jones, S., et al (1991) Self-poisoning patients discharged from accident and emergency: risk factors and outcome. Journal of the Royal College of Physicians of London, 25, 218-222.

Paerregaard, G. (1975) Suicide among attempted suicides: a 10-year follow-up. Suicide, 5, 140-144.

Pallis, D. J., Gibbons, J. S. \& Pierce, D. W. (1984) Estimating suicide risk among attempted suicides. II. Efficiency of predictive scales after the attempt. British Journal of Psychiatry, 144, 139-148.

Palsson, S. P., Jonsdottir, G. \& Petursson, H. (1996) The mortality risk of psychiatric emergency patients. A follow-up study. Nordic Journal of Psychiatry, 50, 207-216.
Pederson, A. M., Awad, G. A. \& Kindler, A. R. (1973) Epidemiological differences between white and nonwhite suicide attempters. American Journal of Psychiatry, 130, 107I-1076.

Pierce, D. W. (198I) The predictive validation of suicide intent scale: a five year follow-up. British Journal of Psychiatry, 139, 391-396.

_ (1984) Suicidal intent and repeated self-harm. Psychological Medicine, 14, 655-659.

Rodger, C. R. \& Scott, A. I. (1995) Frequent deliberate self-harm: repetition, suicide and cost after three or more years. Scottish Medical Journal, 40, 10-12.

Rosen, D. H. (1970) The serious suicide attempt: epidemiological and follow-up study of 886 patients. American Journal of Psychiatry, 127, 764-770.

Rosenman, S. J. (1983) Subsequent deaths after attempted suicide by drug overdose in the western region of Adelaide, 1976. Medical Journal of Australia, 2 496-499.

Ruchholtz, S., Pajonk, F. G., Waydhas, C., et al (1999) Long-term results and quality of life after parasuicidal multiple blunt trauma. Critical Care Medicine, 27, 522 530.

Rygnestad, T. K. (1982) Prospective study of social and psychiatric aspects in self-poisoned patients. Acta Psychiatrica Scandinavica, 66, 139-153.

- (1988) A prospective 5-year follow-up study of selfpoisoned patients. Acta Psychiatrica Scandinavica, 77 328-331. 
Sakinofsky, I., Roberts, R. S., Brown, Y., et al (1990) Problem resolution and repetition of parasuicide. A prospective study. British Journal of Psychiatry, I56, 395-399.

Salander Renberg, E. E. (1999) Parasuicide in a northern Swedish county 1989-1995 and its relation to suicide. Archives of Suicide Research, 5, 97-112.

Salkovskis, P. M., Atha, C. \& Storer, D. (1990)

Cognitive-behavioural problem solving in the treatment of patients who repeatedly attempt suicide. A controlled trial. British Journal of Psychiatry, 157, 87I-876.

Schmidtke, A., Bille-Brahe, U., DeLeo, D., et al (1996) Attempted suicide in Europe: rates, trends and sociodemographic characteristics of suicide attempters during the period 1989-1992. Results of the WHO/ EURO Multicentre Study on Parasuicide. Acta Psychiatrica Scandinavica, 93, 327-338.

Siani, R., Garzotto, N., Tansella, C. Z., et al (1979) Predictive scales for parasuicide repetition. Further results. Acta Psychiatrica Scandinavica, 59, 17-23.

Steer, R. A., Beck, A. T., Garrison, B., et al (1988) Eventual suicide in interrupted and uninterrupted attempters: a challenge to the cry-for-help hypothesis. Suicide and Life-Threatening Behavior, 18, 119-128.

Stocks, R. \& Scott, A. I. F. (1991) What happens to patients who frequently harm themselves? A retrospective one-year outcome study. British Journal of Psychiatry, I58, 375-378.

Sundqvist-Stensman, U. (1988) Suicides among persons treated for self-poisoning at an ICU. Opuscula Medica, 33, 7I-76.

Suokas, J. \& Lonnqvist, J. (1991) Outcome of attempted suicide and psychiatric consultation: risk factors and suicide mortality during a five-year followup. Acta Psychiatrica Scandinavica, 84, 545-549.

Taylor, S. (1998) Training and supervision of deliberate self-harm assessments. Psychiatric Bulletin, 22, 510-512.

Tejedor, M. C., Diaz, A., Castillon, J. J., et al (1999)

Attempted suicide: repetition and survival - findings of a follow-up study. Acta Psychiatrica Scandinavica, 100, 205-2II.

Thies-Flechtner, K., Muller-Oerlinghausen, B., Seibert, W., et al (1996) Effect of prophylactic treatment on suicide risk in patients with major affective disorders - data from a randomized prospective trial. Pharmacopsychiatry, 29, 103-107.

Torhorst, A., Moller, H. J., Kurz, A., et al (1988) Comparing a 3-month and a 12-month outpatient aftercare program for parasuicide repeaters. In Current Issues of Suicidology (eds H. J. Moller, A. Schmidtke \& R.Welz), pp. 419-424. Berlin: Springer-Verlag.

Van der Sande, R., Van Rooijen, L., Buskens, E., et a (1997) Intensive in-patient and community intervention versus routine care after attempted suicide. A randomised controlled intervention study. British Journal of Psychiatry, I7I, 35-4I.

Van Heeringen, C., Jannes, S., Buylaert, W., et al (1995) The management of non-compliance with referral to out-patient after-care among attempted suicide patients: a controlled intervention study. Psychological Medicine, 25, 963-970.

Verkes, R. J., Van der Mast, R. C., Hengeveld, M. W., et al (1998) Reduction by paroxetine of suicidal behavior in patients with repeated suicide attempts but not major depression. Amercian Journal of Psychiatry, I55, 543-547.

Wilkinson, G. \& Smeeton, N. (1987) The repetition of parasuicide in Edinburgh 1980-1981. Social Psychiatry, 22, 14-19.

\section{REFERENCES}

Department of Health (1999) A National Service Framework for Mental Health. London: Department of Health.

Egger, M., Schneider, M. \& Davey-Smith, G. (1998) Spurious precision? Meta-analysis of observational studies. BM/, 316, 140-144.
Gardner, M. J., Gardner, S. B. \& Winter, P. D. (1989) Confidence Interval Analysis (computer program). London: BMJ.

Geddes, J. (1999) Suicide and homicide by people with mental illness. BMJ, 318, 1225-1226.

Gunnell, D. \& Frankel, S. (1994) Prevention of suicide: aspirations and evidence. BMJ, 308, 1227-1233.

Hawton, K., Fagg, J., Simkin, S., et al (1997) Trends in deliberate self-harm in Oxford, 1985-1995. Implications for clinical services and the prevention of suicide. British Journal of Psychiatry, I7I, 556-560.

_, Arensman, E., Townsend, E., et al (1998)

Deliberate self-harm: systematic review of the efficacy of psychosocial and pharmacological treatments in preventing repetition. BMJ, 317, 44I-447.

\section{_ , Townsend, E., Arensman, E., et al (200I)}

Psychosocial and pharmacological treatments for deliberate self harm. The Cochrane Library, issue 2. Oxford: Update Software.

Kapur, N., House, A., Creed, F., et al (1998) Management of deliberate self poisoning in adults in four teaching hospitals: descriptive study. BMJ, 316, 83I-832.

NHS Centre for Reviews and Dissemination (1998) Deliberate self-harm. Effective Health Care, 4 December.

Owens, D. (1990) Self-harm patients not admitted to hospital. Journal of the Royal College of Physicians of London, 24, 28I-283.

— \& House, A. (1994) General hospital services for deliberate self-harm. Journal of the Royal College of Physicians of London, 28, 370-37I.

Rose, G. (1992) The Strategy of Preventive Medicine. Oxford: Oxford University Press.

Secretary of State for Health (1999) Saving Lives. Our Healthier Nation. London: Stationery Office.

Vastag, B. (200I) Suicide prevention plan calls for physicians' help. Journal of the American Medical Association, 285, 270I-2703. 